J. Electroanal. Chem., 115 (1980) 225-233

(C) Elsevier Sequoia S.A., Lausanne - Printed in The Netherlands

\title{
OXYGEN ELECTROSORPTION ON Ag(111) AND Ag(110) ELECTRODES IN NaOH SOLUTION
}

\author{
JOHN M.M. DROOG \\ Van 't Hoff Laboratory, State University of Utrecht, Padualaan 8, Utrecht (The \\ Netherlands)
}

(Received 21st April 1980; in revised form 3rd July 1980)

\begin{abstract}
The first stages of the anodic oxidation of $\mathrm{Ag}(111)$ and $\mathrm{Ag}(110)$ electrodes in $\mathrm{NaOH}$ solution were studied by potential sweep voltammetry and ellipsometry. It was found that in the potential region studied, dissolution of silver species and electrosorption of oxygen occur. The (110) face is much more reactive to oxygen than the (111) face. On $\mathrm{Ag}(110)$ oxygen is reversibly adsorbed via a process of random deposition. The half-width of the adsorption peak indicates attractive lateral interactions in the chemisorbed layer.
\end{abstract}

\section{INTRODUCTION}

In an earlier paper [1] we reported on a study of the first oxidation processes occurring on the bare surface of polycrystalline silver in $\mathrm{NaOH}$ solution. It was shown that two processes occur, namely the dissolution of silver species and the formation of monolayer amounts of silver oxide.

This surface oxide is already formed at potentials that are more negative than the reversible potential for the deposition of bulk silver oxide [1,2]. This means that the chemical potential of the ad-layer differs from that of the corresponding bulk material.

Comparable features have been found, for example, in gas-phase studies of the chemisorption of oxygen on silver [3-6] and in the deposition of lead and thallium on silver electrodes [7-9]. In all these investigations the crystallographic orientation of the silver surface has been found to have a strong influence on the processes studied. Therefore, in order to obtain more detailed information about the processes involved in the anodic oxidation of silver, we decided to study single-crystal substrates with (111) and (110) orientations instead of the polycrystalline substrates of ref. 1 .

Processes such as deposition or desorption of oxygen species can be observed only by a transient technique. Cyclic current-potential curves allow these processes to be studied directly. Any variation in the amount of deposited species can be detected as a current in the voltammogram. Ellipsometry was used to 
obtain additional information, and especially to discriminate between surface oxide formation and dissolution of silver species, just as was done in ref. 1.

Our measurements with single crystals show clearly that the atomic geometry of the metal surface markedly influences the oxide formation; the Ag(110) face electrosorbs much more oxygen than the $\mathrm{Ag}(111)$ face.

\section{EXPERIMENTAL}

The working electrodes were disc-shaped crystals, spark-cut to within $1^{\circ}$ of the desired orientation from $6 \mathrm{~N}$ purity silver rods purchased from Metals Research Ltd. The electrodes were sealed into acrylic resin (Technovite 4071) in such a way that only the top surface of the metal was exposed to the solution. The diameter of the $\mathrm{Ag}(110)$ crystals was $6.4 \mathrm{~mm}$ and that of the $\mathrm{Ag}(111)$ crystals $6.9 \mathrm{~mm}$.

The electrodes were mounted on glass specimen holders, which could be adjusted to allow proper alignment of the specimens for ellipsometry. The electrode surfaces were grazed with carborundum paper, polished with diamond pastes containing diamond particles as small as $0.25 \mu \mathrm{m}$ and finally electro-lappolished (Struers, Denmark, RP-1 electrolyte). In some experiments we used chemically polished electrodes $-15 \mathrm{~s}$ in a mixture of concentrated $\mathrm{NH}_{4} \mathrm{OH}$ and $30 \% \mathrm{H}_{2} \mathrm{O}_{2}$ ( $5: 3$ by volume) [10]. After the electrodes had been polished they were cleaned ultrasonically in twice-distilled water.

Before doing the measurements, we had to reduce cathodically the contaminating layer left from the electropolishing action by maintaining conditions at the electrode surface at the point where hydrogen evolution was just beginning [11-13].

An Ingold "Argenthal" electrode ( $\mathrm{Ag} / \mathrm{AgCl} / \mathrm{KCl}(3 \mathrm{M}) ; E=207 \mathrm{mV}$ vs. NHE), kept separate from the main compartment, served as reference electrode. All potentials quoted in this paper are given with reference to this electrode.

The wavelength of the ellipsometer light was $632.8 \mathrm{~nm}$ and the angle of incidence was $65 \pm 0.5^{\circ}$.

For further experimental details we refer to ref. 1 .

\section{RESULTS}

\section{Cyclic voltammetry measurements}

Linear potential sweep voltammetry curves were recorded at a sweep rate $s=20 \mathrm{mV} \mathrm{s}^{-1}$ for silver single crystals in $1 \mathrm{~mol} \mathrm{dm}^{-3} \mathrm{NaOH}$ with orientations (111) and (110). Figures 1 and 2 show current-potential curves for $\mathrm{Ag}(111)$ and $\mathrm{Ag}(110)$, respectively, with a starting potential of $-500 \mathrm{mV}$ and increasing reversal potentials in the $100-200 \mathrm{mV}$ region. The results obtained were independent of whether the potential scans were single or repetitive. The voltammograms were the same for electrodes that were electro-lap-polished as for electrodes that were chemically polished. When we compare Fig. 1 with Fig. 2 the influence of the atomic geometry of the metal surface on the oxide formation is evident. 


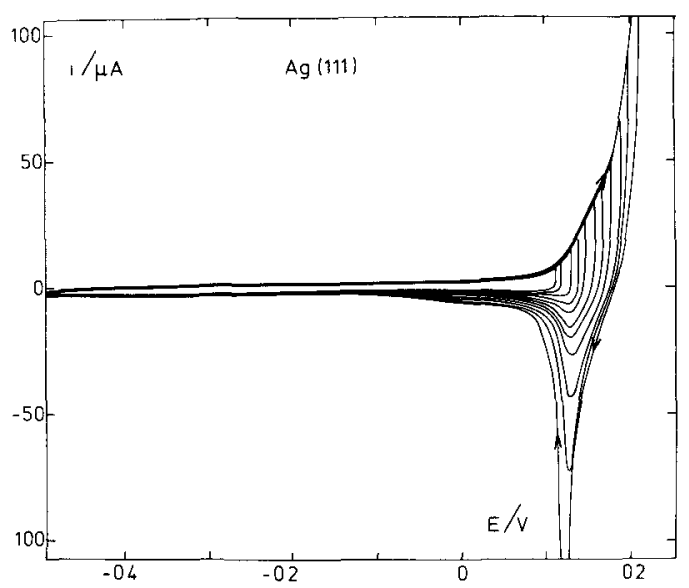

Fig. 1. Potentiodynamic charging curves up to various potentials for $\mathrm{Ag}(111)$ in $1 \mathrm{~mol} \mathrm{dm}^{-3}$ $\mathrm{NaOH}, 22^{\circ} \mathrm{C}, \mathrm{d} E / \mathrm{d} t=20 \mathrm{mV} \mathrm{s}{ }^{-1}$. Apparent surface area $0.37 \mathrm{~cm}^{2}$.

The voltammograms on $\mathrm{Ag}(110)$ clearly show two anodic peaks at potentials negative to the point where bulk oxidation begins, namely at about $170 \mathrm{mV}$. The peak potential $E_{\mathrm{p}}$ of the first peak is $130 \mathrm{mV}$ and the half-width $\Delta E_{1 / 2}$,
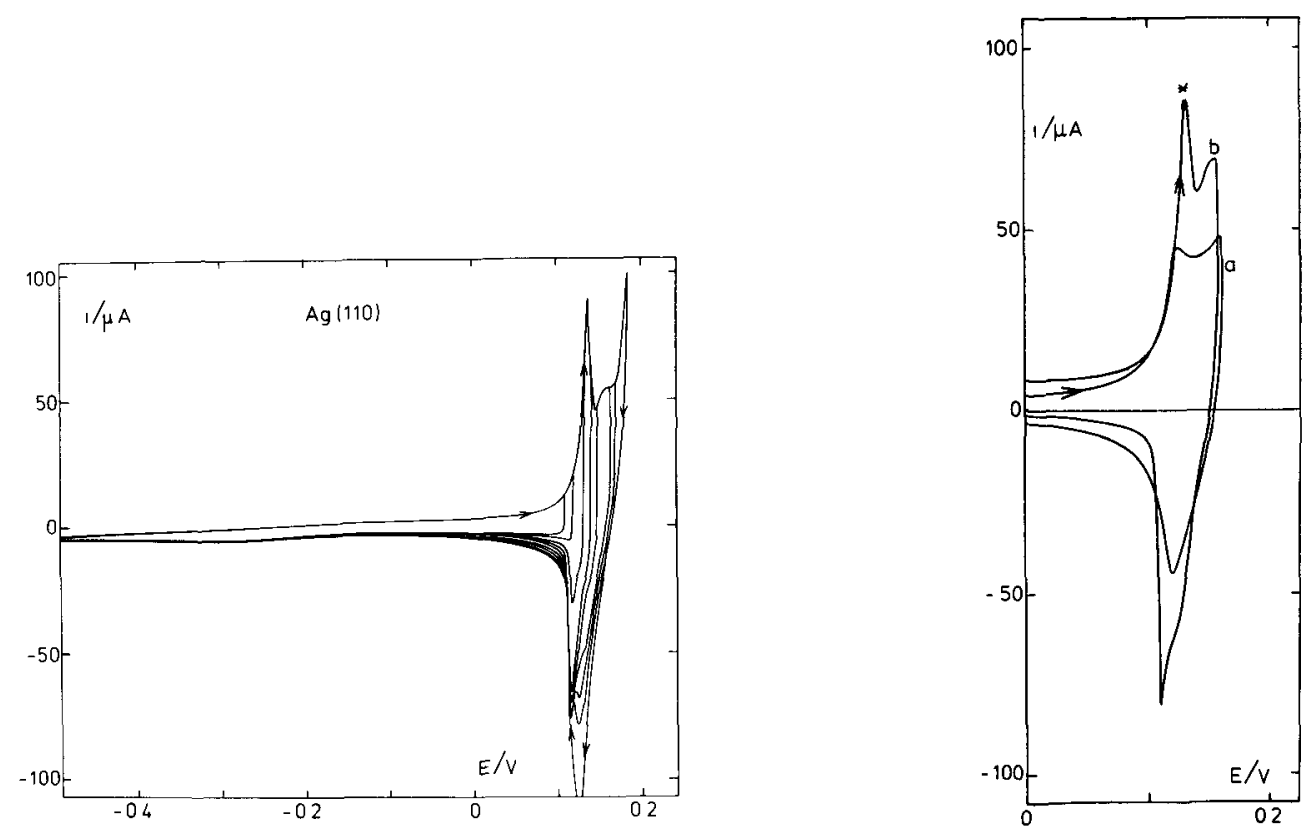

Fig. 2. Potentiodynamic charging curves up to various potentials for $\mathbf{A g}(110)$ in $1 \mathrm{~mol} \mathrm{dm}^{-3}$ $\mathrm{NaOH}, 22^{\circ} \mathrm{C}, \mathrm{d} E / \mathrm{d} t=20 \mathrm{mV} \mathrm{s}^{-1}$. Apparent surface area $0.32 \mathrm{~cm}^{2}$.

Fig. 3. Potentiodynamic charging curves for $\mathrm{Ag}(110)$ in $1 \mathrm{~mol} \mathrm{dm}{ }^{-3} \mathrm{NaOH}, 22^{\circ} \mathrm{C}, \mathrm{d} E / \mathrm{d} t=$ $20 \mathrm{mV} \mathrm{s}^{-1}$. (a) Electrode left in contact with the solution for about $2 \mathrm{~h}$ at a potential of $-500 \mathrm{mV}$; (b) same electrode after $60 \mathrm{~s}$ of hydrogen evolution. 
defined for $i=i_{\mathrm{p}} / 2$, is estimated to be no more than $15 \mathrm{mV}$. The cathodic counterpart of this peak is found at $115 \mathrm{mV}$. The next anodic process is seen as a shoulder at about $155 \mathrm{mV}$, with the cathodic counterpart at $125 \mathrm{mV}$. For reversal potentials where $E_{\mathrm{u}}<150 \mathrm{mV}$, the current reduces almost immediately to cathodic values after reversal of the potential sweep. It was observed that the peak width is dependent on the efficiency of the polishing process. $\mathrm{Ag}(110)$ specimens that were mechanically polished gave wider peaks.

The voltammograms on $\mathrm{Ag}(111)$, on the other hand, reveal a completely different picture. No distinct anodic peaks are seen. Also, the beginning of the bulk oxidation is at a somewhat higher potential than on $\mathrm{Ag}(110)$. The reduction peak is not split up and its peak voltage $E_{\mathrm{p}}$ is $125 \mathrm{mV}$.

It turned out that optimum reproducibility of the results was achieved only for a certain time (generally ca. $\frac{1}{2} \mathrm{~h}$ ) after the electrode had been placed in the solution. Figure 3 shows clearly that in the case of $\operatorname{Ag}(110)$ the shape of the cyclic voltammogram changed considerably when the electrode was left in contact with the solution for several hours. After the electrode potential had been held at a value where hydrogen evolution was just beginning, the original voltammogram could be found again.

When the solution was stirred by vigorous nitrogen bubbling, it was observed that on both planes the anodic current became slightly higher and the cathodic current became slightly lower.

\section{Ellipsometry}

Values for the ellipsometric parameters $\bar{\Delta}$ and $\bar{\psi}$ were measured at an electrode potential of $-500 \mathrm{mV}$. No systematic differences were found between the values for the $\mathrm{Ag}(111)$ and the $\mathrm{Ag}(110)$ surfaces. The optical constants calculated from the values of $\bar{\Delta}$ and $\bar{\psi}[14]$ were $n=0.07 \pm 0.06$ and $k=4.08 \pm$

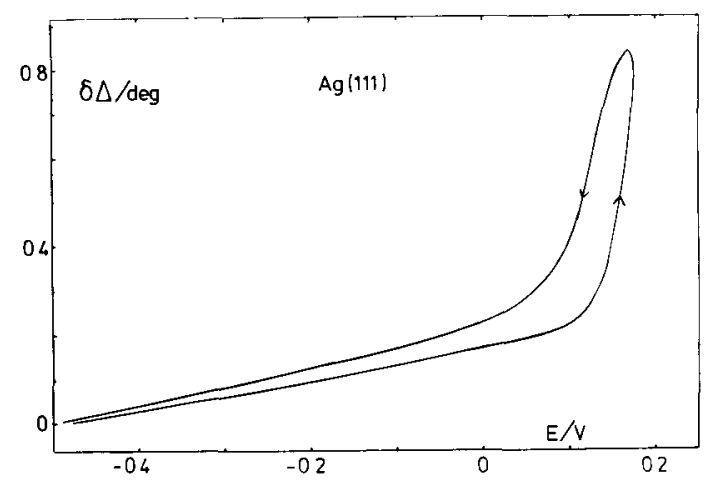

Fig. 4. Change in $\Delta$ during potential scanning up to $176 \mathrm{mV}$. $\mathrm{Ag}(111)$ in $1 \mathrm{~mol} \mathrm{dm}^{-3} \mathrm{NaOH}$, $22^{\circ} \mathrm{C}, \mathrm{d} E / \mathrm{d} t=20 \mathrm{mV} \mathrm{s}^{-1}$. 


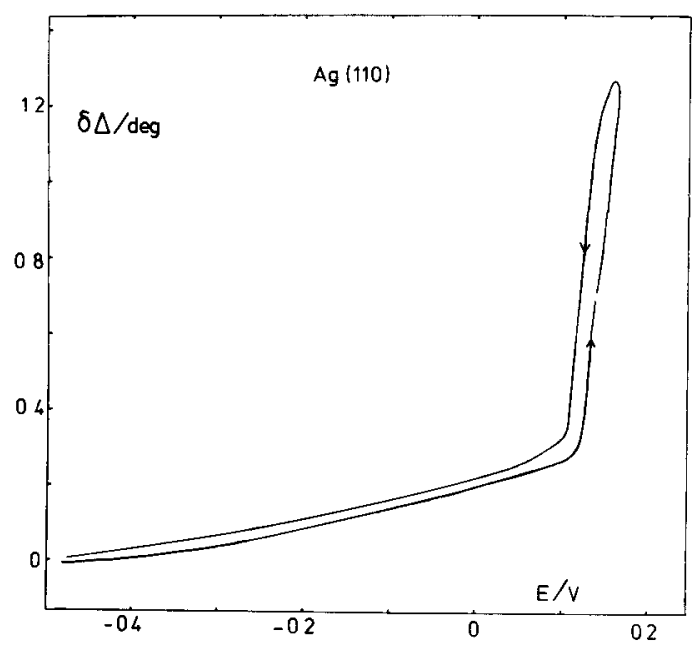

Fig. 5. Change in $\Delta$ during potential scanning up to $163 \mathrm{mV}$. $\mathrm{Ag}(110)$ in $1 \mathrm{~mol} \mathrm{dm}{ }^{-3} \mathrm{NaOH}$, $22^{\circ} \mathrm{C}, \mathrm{d} E / \mathrm{d} t=20 \mathrm{mV} \mathrm{s}^{-1}$.

0.10. Control experiments showed that the light from the laser source and the room light had no influence on the voltammograms.

Figures 4 and 5 give typical examples of the changes in $\Delta$ as a function of the potential during a triangular potential sweep. The parameter $\delta \Delta$ is defined by $\delta \Delta=\bar{\Delta}-\Delta$. These transient measurements were obtained by lightintensity monitoring with the analyser in its extinction position for the filmfree surface at $-500 \mathrm{mV}$ and the polarizer offset from its null position [15-17]. Measurements carried out on both sides of the null setting gave identical results for $\delta \Delta$, showing that changes in $\psi$ and in the reflectivity did not contribute to the light-intensity changes. Figures 4 and 5 show a slow increase in $\delta \Delta$ in the $-500 \mathrm{mV}$ to $+100 \mathrm{mV}$ region. Just above $100 \mathrm{mV}$ the increase is much sharper. The maximum $\delta \Delta$ is greater for the $\operatorname{Ag}(110)$ face than for the $\operatorname{Ag}(111)$ face under comparable circumstances. For the (110) surface, the slope is steepest at about $130 \mathrm{mV}$. For both faces, the decrease in $\delta \Delta$ during the negative sweep begins rapidly, but the (110) face shows less hysteresis.

\section{Measurements at different sweep rates}

For both planes voltammograms were measured with sweep rates $s$ varying between $5 \mathrm{mV} \mathrm{s}^{-1}$ and $2000 \mathrm{mV} \mathrm{s}^{-1}$ and a scan reversal potential of $155 \mathrm{mV}$. The dependences of peak potential, charge and change in $\Delta$ on $s$ were investigated.

On the $\mathrm{Ag}(110)$ face the peak potentials of the sharp adsorption peak at 130 $\mathrm{mV}$ and the desorption peak at $115 \mathrm{mV}$ (see Fig. 2) were exactly the same for voltammograms with $s$ between $5 \mathrm{mV} \mathrm{s}^{-1}$ and $200 \mathrm{mV} \mathrm{s}^{-1}$. Between $s=200 \mathrm{mV}$ $\mathrm{s}^{-1}$ and $s=2000 \mathrm{mV} \mathrm{s}^{-1}$ the peak potentials shifted about $10 \mathrm{mV}$, the anodic 


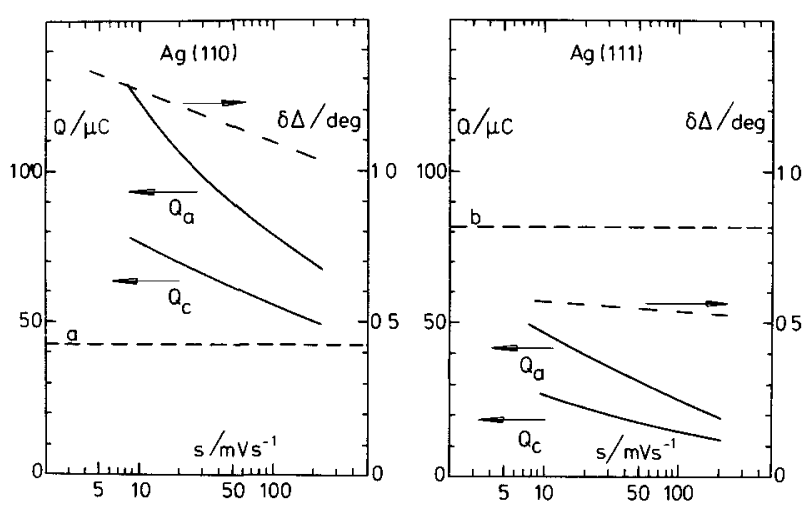

Fig. 6. $Q_{\mathrm{a}}, Q_{\mathrm{c}}$ and $\delta \Delta$ vs. sweep rate. Reversal potential $E_{\mathrm{u}}=155 \mathrm{mV}$. (a, b) Charges for monolayer of $\mathrm{Ag}(\mathrm{I})$ atoms.

peak to a higher potential, the cathodic peak to a lower potential.

In Fig. 6 the anodic and cathodic charges $Q_{\mathrm{a}}$ and $Q_{\mathrm{c}}$ and the maximum $\delta \Delta$ during the potential sweep are plotted vs. the sweep rate. The anodic charges are larger than the cathodic ones. It can also be seen that the relative decrease in $\delta \Delta$ is smaller than the relative decrease in $Q_{a}$ and $Q_{c}$. On our electrodes, assuming the roughness factor to be equal to unity, the charges relating to a monolayer of $\mathrm{Ag}(\mathrm{I})$ atoms are 82 and $43 \mu \mathrm{C}$ for the $\mathrm{Ag}(111)$ and $\mathrm{Ag}(110)$ face respectively. These values are shown in Fig. 6.

\section{DISCUSSION}

As can be shown by a comparison of the respective voltammograms (Figs. 1 and 2) and ellipsometric curves (Figs. 4 and 5) the (110) face of silver is more reactive towards hydroxide ion than the (111) face.

On both planes the anodic charge $Q_{\mathrm{a}}$ is greater than the cathodic charge $Q_{\mathrm{c}}$. Also, it follows from the experiments with different sweep rates (Fig. 6) that $\delta \Delta$ is not proportional to $Q_{\mathrm{a}}$ and $Q_{\mathrm{c}}$. From these features, we conclude that oxygen electrosorption accompanied by dissolution of silver species occurs on both $\mathrm{Ag}(111)$ and $\mathrm{Ag}(110)$. (see ref. 1). The constancy of the potentiodynamic $i / E$ curves shows that the dissolution does not lead to measurable surface roughening and production of other crystal planes.

On the (111) face the voltammogram with $E_{\mathrm{u}}=155 \mathrm{mV}$ and $s=20 \mathrm{mV} \mathrm{s}^{-1}$ gives a charge of $22 \mu \mathrm{C}$ under the cathodic peak; this is much less than the 82 $\mu \mathrm{C}$ charge associated with the formation of a monolayer of monovalent silver atoms. Therefore, the possibility cannot be excluded that on this plane the oxygen adsorbs at irregularities on the surface, as was found by Albers et al. for oxygen chemisorption from the gas phase $[3,4,6]$. Albers found that very carefully annealed $\mathrm{Ag}(111)$ surfaces adsorbed hardly any oxygen. 


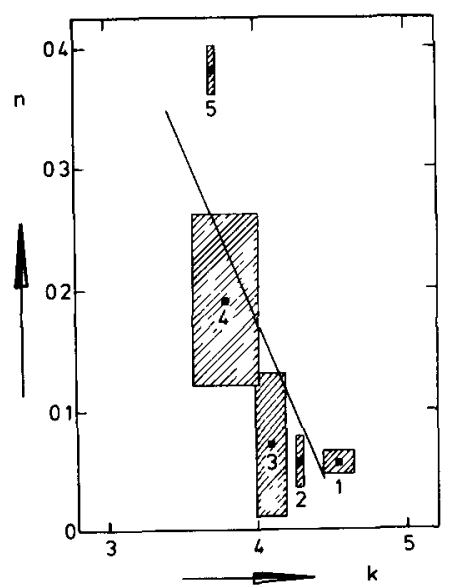

Fig. 7. Optical constant of Ag at $632.8 \mathrm{~nm}$. (1) Single crystal in UHV [3,6]; (2) film in UHV [27 ], (3) single crystal in electrolyte [this work]; (4) polycrystalline in electrolyte [1];

(5) polycrystalline in electrolyte [28]. The drawn line denotes ion-bombarded $\mathrm{Ag}[3,6]$.

It is known $[18,19]$ that unannealed films, polycrystalline samples and ionbombarded single crystals show a tendency to larger $n$ and smaller $k$ values Figure 7 shows a number of experimentally determined values for $\mathrm{Ag}$ at $\lambda=$ $632.8 \mathrm{~nm}$. Our $n$ and $k$ values are in between the values for polycrystalline samples and those for the annealed single crystals of Albers [3,6].

For the $\mathrm{Ag}(110)$ face the voltammogram (Fig. 2) shows two dinstinct adsorption peaks. The sharpness of the first peak indicates the presence of attractive lateral interactions. If adsorption follows a Langmuir isotherm, then the half-width of the adsorption peak is equal to $90 \mathrm{mV} z^{-1}$. In the more general case of a Frumkin isotherm, which takes into account the interaction between the adsorbed particles, the half-width should be larger if there is repulsion (interaction parameter $g>0)$ and smaller if there is attraction $(g<0)$ $[20,21]$. Lateral interactions corresponding to $g \leqslant-4$ would lead to the formation of a nucleus [22].

Figure 2 shows that there is a separation of about $15 \mathrm{mV}$ on the potential axis between the deposition $\left(E_{\mathrm{p}}=130 \mathrm{mV}\right)$ and the stripping process $\left(E_{\mathrm{p}}=\right.$ $115 \mathrm{mV}$ ). This separation is not due to slow kinetics, since it is observed at sweep rates where the peak potentials are independent of the sweep rate. Bewick and Thomas have observed the same phenomenon for the underpotential deposition of lead on silver substrates [23]. They argued that such a separation results from a nucleation overpotential and is therefore proof that the adsorption mechanism incorporates a nucleation step.

However, the only clear basis for distinguishing a nucleation-controlled process from a random deposition process is given by the effect of reversing the potential sweep before the current has reached its peak value. For the nucleation-controlled process, reversal of the sweep before the growing islands overlap 
produces a characteristic continuing increase of current, since growth around the growth centres continues along longer perimeters in the reversed sweep, and new nuclei continue to be formed [24]. This has been found experimentally for example in the three-dimensional case of bulk formation of AgO on silver electrodes in alkaline solutions $[25,26]$.

The voltammograms for $\mathrm{Ag}(110)$ given in Fig. 2 show that reversal of the direction of the sweep immediately produces negative currents. Therefore, the electrodeposition must be a random deposition process and not a nucleationcontrolled one. Since the peak potentials are independent of the sweep rate, the peaks are of the reversible kind. The hysteresis that the overall process exhibits could point to some irreversible transformation of the initially reversibly electrosorbed species, reducible only at slightly less positive potentials than those required for its deposition.

The fact that on mechanically polished $\mathrm{Ag}(110)$ specimens, i.e. surfaces with more defects, the adsorption peaks are smaller and wider indicates that the adsorption behaviour of Fig. 2 is related to majority sites and not to (minority) defects.

The effect of the electrode electrolyte contact time shown in Fig. 3 can be explained by contamination of the surface. This means that a number of adsorption sites are blocked and are no longer active in the chemisorption of oxygen species. Apparently adsorbed impurities can be removed at potentials where hydrogen evolution is just beginning.

\section{CONCLUSION}

During the initial stage of the anodic oxidation of silver single crystals in $\mathrm{NaOH}$ solution dissolution of silver species and electrosorption of oxygen occur. The,atomic geometry of the surface markedly influences the oxygen chemisorption; the $\mathrm{Ag}(110)$ plane is much more reactive than the $\mathrm{Ag}(111)$ plane. On $\mathrm{Ag}(110)$ oxygen adsorbs reversibly via a process of random deposition. The half-width of the adsorption peak indicates attractive lateral interactions in the chemisorbed layer.

\section{ACKNOWLEDGEMENTS}

Discussions with Prof. G.A. Bootsma and Prof. J.H. Sluyters were greatly appreciated and I thank Mr. T.L. Schroote for his help in polishing the specimens.

\section{REFERENCES}

1 J.M.M. Droog, P.T. Alderliesten and G.A. Bootsma, J. Electroanal. Chem., 99 (1979) 173.

2 R.D. Giles and J.A. Harrison, J. Electroanal. Chem., 27 (1970) 161.

3 H. Albers, J.M.M. Droog and G.A. Bootsma, Surf. Sci., 64 (1977) 1.

4 H. Albers, W.J.J. van der Wal and G.A. Bootsma, Surf. Scl., 68 (1977) 47.

5 H. Albers, W.J.J. van der Wal. O.L.J. Gijzeman and G.A. Bootsma, Surf. Sc1., 77 (1978) 1. 
6 H. Albers, Thesıs, University of Utrecht, 1978.

7 F. Hilbert and J. Kumbacher, Surf. Technol., 5 (1977) 135.

8 A. Bewick and B. Thomas, J. Electroanal. Chem., 84 (1977) 127.

9 H. Siegenthalex, K. Juttner, E. Schmidt and W.J. Lorenz, Electrochim. Acta, 23 (1978) 1009.

10 T.E. Furtak and J.K. Sass, Surf. Sci., 78 (1978) 591.

11 G. Valette and A. Hamelin, J. Electroanal. Chem., 45 (1973) 301.

12 T.E. Furtak and D.W. Lynch, J. Electroanal. Chem., 79 (1977) 1.

13 T.E. Furtak, J. Phys., 38 (1977) C5-233.

14 R.W. Ditchburn, J. Opt. Soc. Am., 45 (1955) 743.

15 A.K.N. Reddy and B. Rao, Can. J. Chem., 47 (1969) 2687.

16 Y.-C. Chiu and M.A. Genshaw, J. Phys. Chem., 73 (1969) 3571.

17 J.J. Carroll and A.J. Melmed, Surf. Sc1., 16 (1969) 251.

18 F.H.P.M. Habraken, O.L.J. Guzeman and G.A. Bootsma, Surf. Sc1., submitted.

19 F.H.P.M. Habraken, Thesis, University of Utrecht, 1980.

20 E. Gleadi and B.E. Conway in B.E. Conway and J.O'M. Bockris (Eds.), Modern Aspects of Electrochemistry, Vol. 3, Butterworths, London, 1964, Ch. 5.

21 A. Sadkowski, J. Electroanal. Chem., 97 (1979) 283.

22 H. Angerstein-Kozlowska, J. Klinger and B.E. Conway, J. Electroanal. Chem., 75 (1977) 45.

23 A. Bewick and B. Thomas, J. Electroanal. Chem., 85 (1977) 329.

24 H. Angersteın-Kozlowska, B.E. Conway and J. Klinger, J. Electroanal. Chem., 87 (1978) 301.

25 P. Stonehart and F.P. Portante, Electrochım. Acta, 13 (1968) 3437.

26 J.M.M. Droog and F. Huisman, J. Electroanal. Chem., 115 (1980) 211 (this issue).

27 P.B. Johnson and R.W. Christy, Phys. Rev. B, 6 (1972) 4370.

28 Z.I. Kudryavtseva, N.A. Shumlova, V.A. Openkın, N.A. Zhuchkova and E.I. Khrushcheva, Sov. Electrochem., 13 (1977) 608. 